\title{
Functional and anatomical characterization of a non-leaking bilateral cystoid macular edema induced by paclitaxel therapy for ovarian cancer: a case report
}

\author{
Stephan Hoffmann ( $\nabla$ dr.shoffmann@gmail.com ) \\ Universitat des Saarlandes \\ David Ganster \\ Landeskrankenhaus Feldkirch \\ Patrick Sidoroff \\ Landeskrankenhaus Feldkirch \\ Stefan Mennel \\ Landeskrankenhaus Feldkirch
}

\section{Case report}

Keywords: Paclitaxel, macular edema, ovarian cancer, microperimetry, fluorescence angiography

Posted Date: July 3rd, 2019

DOl: https://doi.org/10.21203/rs.2.9465/v1

License: (c) (i) This work is licensed under a Creative Commons Attribution 4.0 International License.

Read Full License 


\section{Abstract}

Abstract: Background: Paclitaxel is a member of the taxane family used for cancer therapy. Ovarian cancer is treated with Paclitaxel in first- and in second- line therapy. Cystoid macular edema without fluorescein leakage is a rare side effect of Paclitaxel treatment. Case presentation: We report the case of a 59-year-old female with ovarian cancer treated with paclitaxel. The patient received 21 cycles of adjuvant chemotherapy and was presented with bilateral gradual vision loss due to macular edema after paclitaxel treatment. Optical coherence tomography revealed a bilateral cystoid macular edema. Fluorescence angiography demonstrated the unusual finding of non-leakage in the late phases of the angiogram. Microperimetric findings of both eyes confirmed the visual deficits. After cessation of the paclitaxel therapy, vision, OCT and microperimetric findings returned to normal. Also, color vision testing demonstrated no persistent defect after therapy cessation. Conclusion: Paclitaxel induced bilateral maculopathy is a rare side effect of chemotherapy. Cessation of the Paclitaxel drug therapy leads to complete functional and anatomical resolution of drug induced side effects. Vision, microperimetric defects, color perception as also anatomical defects detected by OCT change to normal after drug cessation. Taxane induced bilateral maculopathy is a rare disease which should be known by ophthalmologists as also oncologists. Paclitaxel therapy must be counseled to report any vision problems during the treatment period because early recognition of a rare non leaking CME can facilitate appropriate intervention to reverse visual compromise and minimize any potential long-term ophthalmologic sequelae.

\section{Background}

Paclitaxel is a member of the taxane family used in various chemotherapeutical protocols for the treatment of ovarian cancer, lung cancer and breast cancer.[1] They are mitotic inhibitors, preventing normal reorganization of the microtubule network within cells [2]. Side effects of the drug are involving neurological disorders as also diseases of the eye. Bone marrow suppression, vomiting, alopecia and nausea have been described as systemic side effects. More rarely are ophthalmic side effects of the drug. A bilateral cystic macula edema with no leakage in fluorescence angiography is a rare side effect of Paclitaxel[3, 4] . Other retinal diseases demonstrating a cystoid macular edema with non-angiographic leakage are juvenile X-chromosomal Retinoschisis, Goldman-Favre Syndrome, several forms of Retinitis pigmentosa as also Niacine toxicity of the macula[5-11] . Anatomical restauration and vision increase have been described after cessation of the drug, but also non-vision increase has been reported $[1,3,4$, 12-34].

\section{Case Presentation}

We report the case of 59-year-old female presenting with gradual bilateral vison loss. The patient was treated with adjuvant Paclitaxel chemotherapy for ovarian cancer and had received 21 cycles from 6/17 to $12 / 17$. The cumulative dose of the drug was $2708 \mathrm{mg}$. Systemic diseases as diabetes and 
hypertension were not reported. Cataract surgery of both eyes was performed two years ago. Also, childhood strabism resulting in amblyopia of the right eye was reported.

Other diseases of the eye or surgeries were not reported. The visual acuity of both eyes was 0.5 at the initial presentation and did not improve through the use of lenses. No vision disturbing anomalies of the anterior eye section were seen on examination. Funduscopy of the retina revealed a macular edema (Fig.1). The eye pressure was in the normal physiologic range.

Spectral domain coherence tomography (OCT) (Heidelberg Spectralis OCT, Heidelberg GmbH, Heidelberg, Germany) scans revealed an increased bilateral macular thickness due to intraretinal fluid accumulation (Fig.4,5). Despite the OCT results demonstrating a cystoid maculopathy, the fluorescence angiography (FA) (Heidelberg Spectralis, Heidelberg GmbH, Heidelberg, Germany) (Fig.7-8) as also the indocyanine angiography (ICG) (Fig.9-10) showed no leakage and therefore no impairment of the blood retinal barrier. These results are consistent with the diagnosis of a cystoid macula edema without leakage. Fundus autofluorescence disclosed no pathologies (Fig. 6). Microperimetry of both eyes (MAIA-microperimetry, Centervue, Padua, Italy) confirmed the visual deficits on a functional basis. Fixation problems of both eyes were detected as also a decreased sensitivity shift (Fig. 2,3).

Bilateral paclitaxel induced non-leaking maculopathy was diagnosed and chemotherapy treatment was discontinued. Five weeks after chemotherapy discontinuation, the vision increased to 0.6 on the right eye and 1.0 on the left eye. OCT disclosed the complete anatomical resolution of the previous presented macular edema (Fig. 11). Microperimetry showed also the functional restauration of the fovea (Fig. 12, 13) as also a panel D-15 color test (Fig. 14). Microperimetry demonstrated an increased sensitivity of the fovea to the stimuli and a normal fixation performance. A later clinical control 9 weeks after chemotherapy cessation showed also a further vision increase of the amblyopic right eye to 0.8 . The vision of the left eye stabilized at 1.0.

\section{Discussion And Conclusions}

The differential diagnosis for cystoid macula edema without angiographic leakage includes nicotinic acid- associated maculopathy, X-linked juvenile retinoschisis, various forms of retinitis pigmentosa and taxane-associated maculopathy $[3,6-11,13,14,17,22,33,34]$.

Taxane are a group of chemotherapeutic drugs that are used to treat several malignancies such as breast, lung and ovarian cancer. Paclitaxel (Taxol) is a microtubule-stabilizing agent which belongs to the Taxane family [35]. A bilateral, angiographically non-leaking cystoid macular edema is a seldom side effect of the drug especially after high cumulative doses. Imaging in Paclitaxel-related CME reveals fluid on ocular coherence tomography scan without leakage on fundus fluorescein angiography, which is in keeping with our findings. There are no recommended treatment guidelines for this condition because of the unclear mechanism of pathology. Treatment strategies have focused on Paclitaxel cessation, which appears to result in spontaneous resolution of CME and improvement in visual acuity $[13,15,16,22,26$, 32]. 
Color vision and microperimetric function of the fovea display other values characterizing foveal function. Until now, these parameters have not been evaluated after cessation of Paclitaxel.

Our group used for the first time microperimetry to evaluate the effects on paclitaxel on macular function. We were able to demonstrate fixation loss, loss of fixation stability as also macular sensitivity by Paclitaxel therapy for ovarian cancer. All parameters returned to normal after Paclitaxel cessation. These functional improvements demonstrate the importance to identify Paclitaxel maculopathy in early stages and initiate directly the cessation of the drug to improve vision and macular function.

\section{Abbreviations}

OCT: ocular coherence tomography, CME: cystoid macula edema, ICG: indocyanine green angiography

\section{Declarations}

Ethics approval and consent to participate: Not applicable

Acknowledgment: Not applicable

Funding: None

Availability of data and materials: All data generated are included in this published article.

\section{Authors' contributions:}

SH participated in the design of the study and wrote the manuscript. DG, PS,SM conceived the study and participated in its design and coordination and helped to draft the manuscript. All authors read and approved the final manuscript.

\section{Consent for publication:}

Written informed consent was obtained from the patient for publication of this case report and any accompanying images.

Competing interests:

The authors declare that they have no competing interests.

\section{References}

1. Boere IA, van der Burg ME: Review of dose-intense platinum and/or paclitaxel containing chemotherapy in advanced and recurrent epithelial ovarian cancer. Curr Pharm Des 2012, 18(25):3741-3753. 
2. Crabtree DV, Ojima I, Geng X, Adler AJ: Tubulins in the primate retina: evidence that xanthophylls may be endogenous ligands for the paclitaxel-binding site. Bioorg Med Chem 2001, 9(8):1967-1976.

3. Kashiwagi $\mathrm{H}$ : [Ocular disorders of anticancer drugs-ocular side effects]. Gan To Kagaku Ryoho 2010, 37(9):1639-1644.

4. Li J, Tripathi RC, Tripathi BJ: Drug-induced ocular disorders. Drug Saf 2008, 31(2):127-141.

5. Altschwager P, Ambrosio L, Swanson EA, Moskowitz A, Fulton AB: Juvenile Macular Degenerations. Semin Pediatr Neurol 2017, 24(2):104-109.

6. Berenberg TL, Van Tassel SH, Patel SN, Chan RV: Juvenile X-Linked Retinoschisis: A Comparison of Imaging Modalities and Review of Angiographic Findings. Retina 2016, 36(12):e117-e119.

7. Domanico D, Verboschi F, Altimari S, Zompatori L, Vingolo EM: Ocular Effects of Niacin: A Review of the Literature. Med Hypothesis Discov Innov Ophthalmol 2015, 4(2):64-71.

8. Gass JD: Nicotinic acid maculopathy. Am J Ophthalmol 1973, 76(4):500-510.

9. Gass JD: Nicotinic acid maculopathy. 1973. Retina 2003, 23(6 Suppl):500-510.

10. North V, Gelman R, Tsang SH: Juvenile-onset macular degeneration and allied disorders. Dev Ophthalmol 2014, 53:44-52.

11. Sieving PA, MacDonald IM, Chan S: X-Linked Juvenile Retinoschisis. In: GeneReviews $((R))$. edn. Edited by Adam MP, Ardinger HH, Pagon RA, Wallace SE, Bean LJH, Stephens K, Amemiya A. Seattle (WA); 1993.

12. Baskin DE, Garg SJ: Abraxane-induced cystoid macular edema refractory to concomitant intravenous bevacizumab. Can J Ophthalmol 2011, 46(2):200-201.

13. Bassi E, Loizzi V, Furino C, Martino R, Alessio G, Ettore C, Cormio G: Cystoid macular edema secondary to paclitaxel therapy for ovarian cancer: A case report. Mol Clin Oncol 2017, 7(2):285-287.

14. Chang SY, Tsai SH, Chen LJ, Chan WC: Paclitaxel-induced cystoid macular oedema. Acta Ophthalmol 2018, 96(5):e649-e650.

15. Chelala E, Arej N, Antoun J, Kourie HR, Zaarour K, Haddad FG, Farhat F, El Karak F, Kattan J: Central Macular Thickness Monitoring after a Taxane-Based Therapy in Visually Asymptomatic Patients. Chemotherapy 2017, 62(3):199-204.

16. Dwivedi R, Tiroumal S: Possible Efficacy of Topical Dorzolamide in the Treatment of PaclitaxelRelated Cystoid Macular Edema. Retin Cases Brief Rep 2018, 12(1):75-79.

17. Georgakopoulos CD, Makri OE, Vasilakis P, Exarchou A: Angiographically silent cystoid macular oedema secondary to paclitaxel therapy. Clin Exp Optom 2012, 95(2):233-236.

18. Hofstra LS, de Vries EG, Willemse PH: Ophthalmic toxicity following paclitaxel infusion. Ann Oncol 1997, 8(10):1053.

19. Joshi MM, Garretson BR: Paclitaxel maculopathy. Arch Ophthalmol 2007, 125(5):709-710.

20. Koo NK, Kim YC: A case of paclitaxel-induced maculopathy treated with methazolamide. Korean $J$ Ophthalmol 2012, 26(5):394-397. 
21. Kuwata M, Yoshizawa K, Matsumura M, Takahashi K, Tsubura A: Ocular toxicity caused by Paclitaxel in neonatal sprague-dawley rats. In Vivo 2009, 23(4):555-560.

22. Modi D, Dubovy SR: Non-leaking Cystoid Maculopathy Secondary to Systemic Paclitaxel. Ophthalmic Surg Lasers Imaging Retina 2013, 44(2):183-186.

23. Murphy CG, Walsh JB, Hudis CA, Lake D, Theodoulou M: Cystoid macular edema secondary to nabpaclitaxel therapy. J Clin Oncol 2010, 28(33):e684-687.

24. Nakao S, Ikeda Y, Emi Y, Ishibashi T: Possibility of Muller Cell Dysfunction as the Pathogenesis of Paclitaxel Maculopathy. Ophthalmic Surg Lasers Imaging Retina 2016, 47(1):81-84.

25. Nomi N, Ota M, Fukumura M, Nuno Y, Hatano M, Wakuta M, Yanai R, Kimura K: Indocyanine green angiography findings of cystoid macular edema secondary to paclitaxel therapy. Jpn J Ophthalmol 2018, 62(2):163-167.

26. Rahimy E, Sarraf D: Cystoid macular edema secondary to nanoparticle albumin-bound Paclitaxel therapy. Ophthalmic Surg Lasers Imaging Retina 2013, 44(2):187-189.

27. Rao RC, Choudhry N: Cystoid macular edema associated with chemotherapy. CMAJ 2016, 188(3):216.

28. Risard SM, Pieramici DJ, Rabena MD: Cystoid macular edema secondary to Paclitaxel (abraxane). Retin Cases Brief Rep 2009, 3(4):383-385.

29. Scaioli V, Caraceni A, Martini C, Curzi S, Capri G, Luca G: Electrophysiological evaluation of visual pathways in paclitaxel-treated patients. J Neurooncol 2006, 77(1):79-87.

30. Shih CH, Lee YC: Impaired retinal pigment epithelium in paclitaxel-induced macular edema: A case report. Medicine (Baltimore) 2018, 97(26):e11229.

31. Smith SV, Benz MS, Brown DM: Cystoid macular edema secondary to albumin-bound paclitaxel therapy. Arch Ophthalmol 2008, 126(11):1605-1606.

32. Sridhar J, Shahlaee A, Ehmann D, Samara WA, Rahimy E, Ho AC, Chiang A: En Face Optical Coherence Tomography and Optical Coherence Tomography Angiography Imaging of TaxaneAssociated Cystoid Macular Edema. Ophthalmic Surg Lasers Imaging Retina 2016, 47(2):176-179.

33. Teitelbaum BA, Tresley DJ: Cystic maculopathy with normal capillary permeability secondary to docetaxel. Optom Vis Sci 2003, 80(4):277-279.

34. Telander DG, Sarraf D: Cystoid macular edema with docetaxel chemotherapy and the fluid retention syndrome. Semin Ophthalmol 2007, 22(3):151-153.

35. van der Burg ME, Vergote I, Onstenk W, Boere IA, Leunen K, van Montfort CA, van Doorn HC: Longterm results of weekly paclitaxel carboplatin induction therapy: an effective and well-tolerated treatment in patients with platinum-resistant ovarian cancer. Eur J Cancer 2013, 49(6):1254-1263.

\section{Figures}



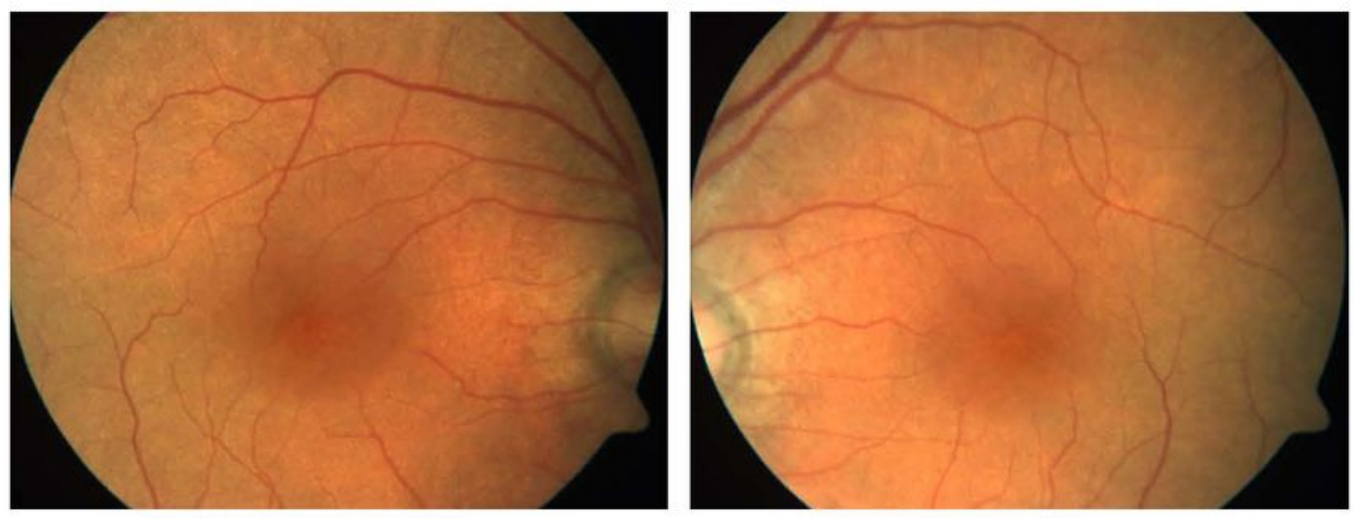

Figure 1

\section{Figure 1}

Fundus photography of the right and left retina at first presentation
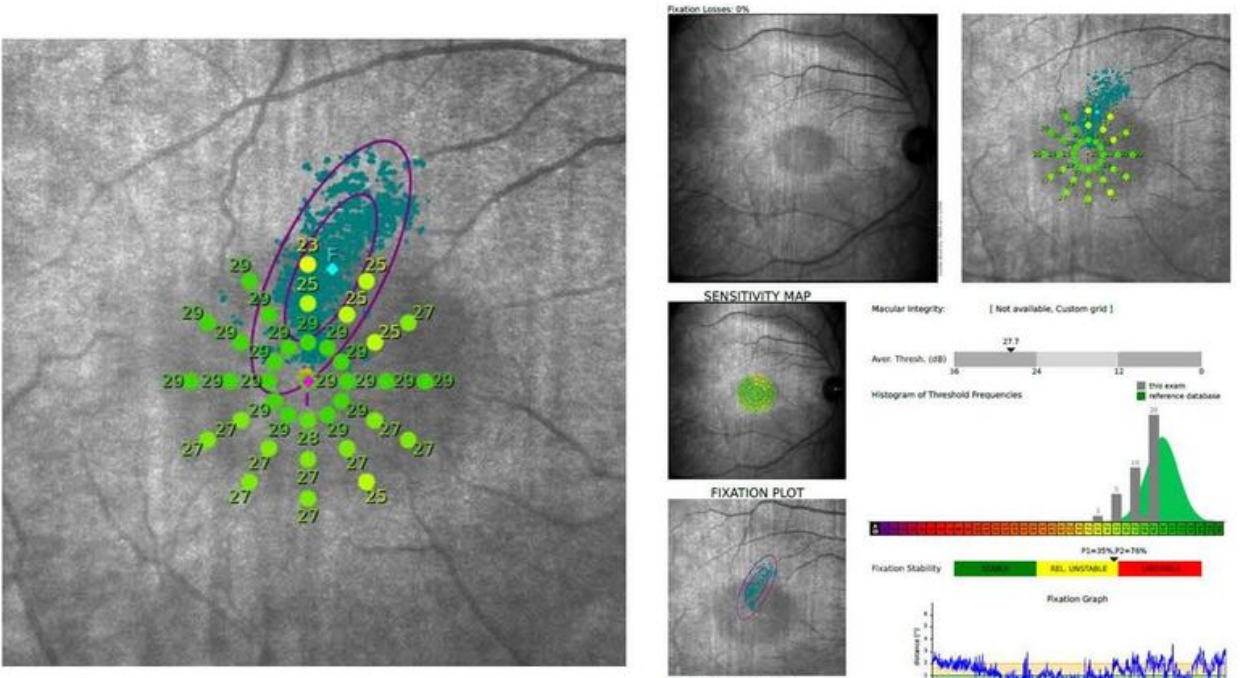

क⿻上丨

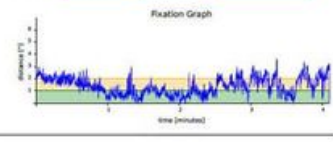

Figure 2 
Figure 2

Microperimetry of the right eye at first presentation of the patient
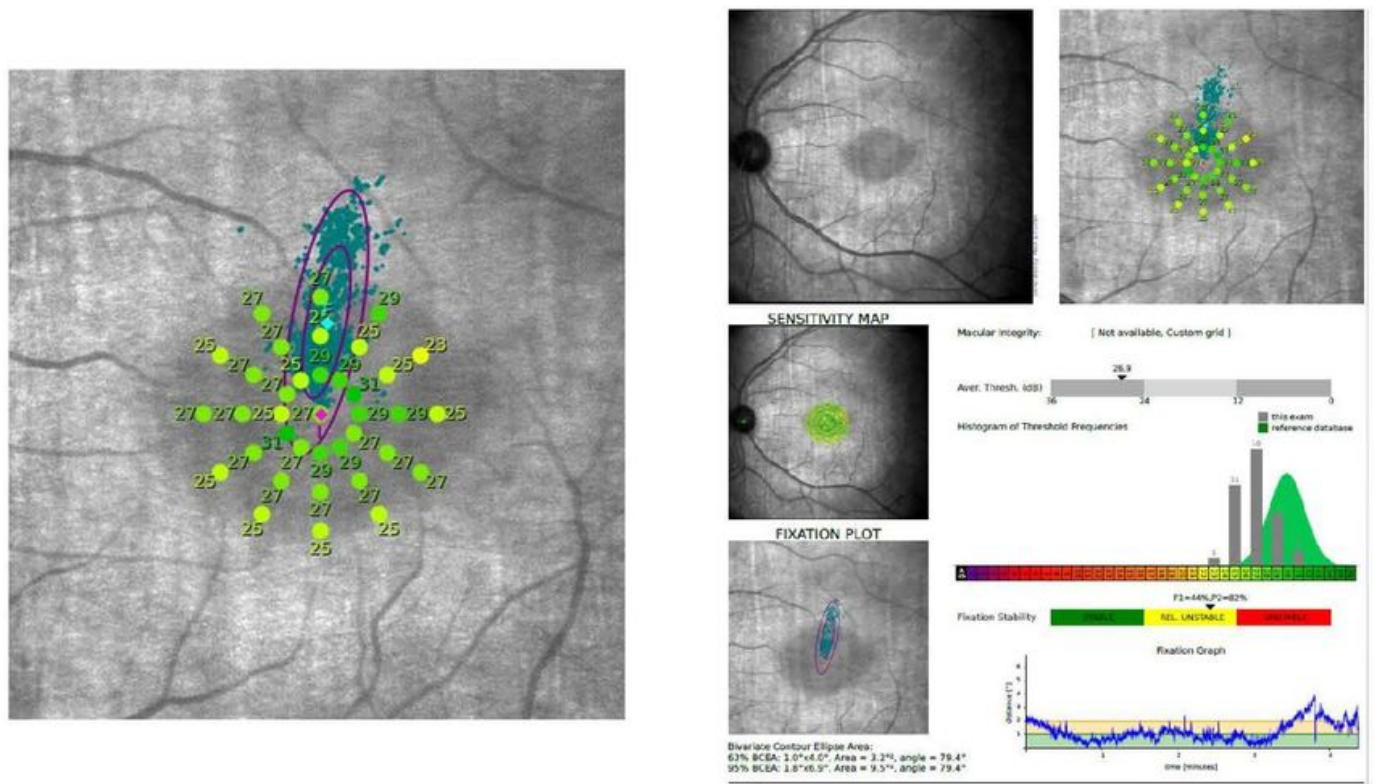

Figure 3

\section{Figure 3}

Microperimetry of the left eye at first presentation of the patient 


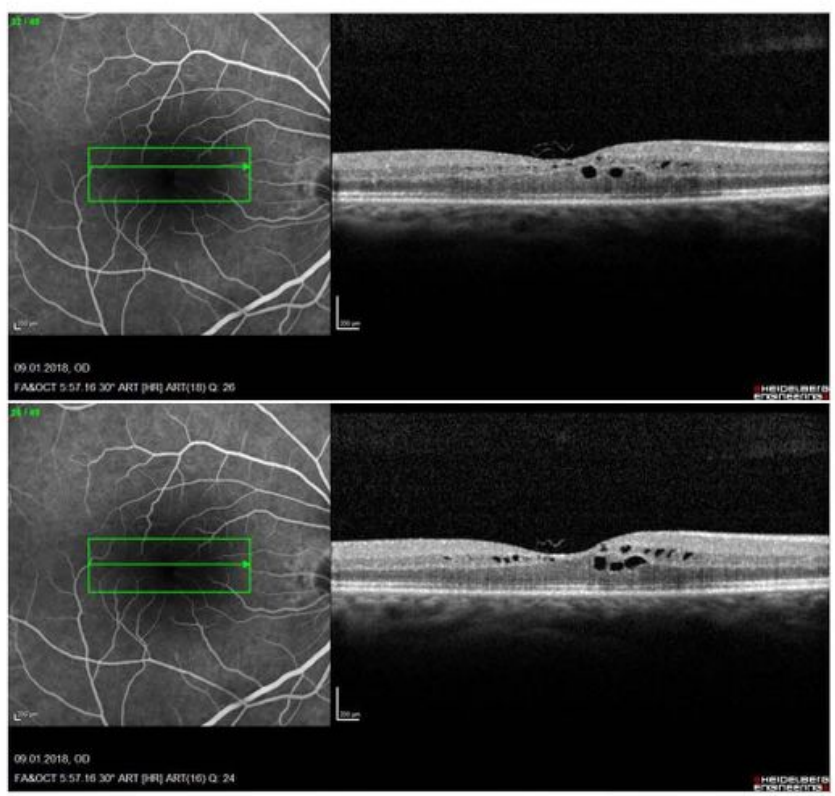

Figure 4

Figure 4

OCT of the right macula at first presentation

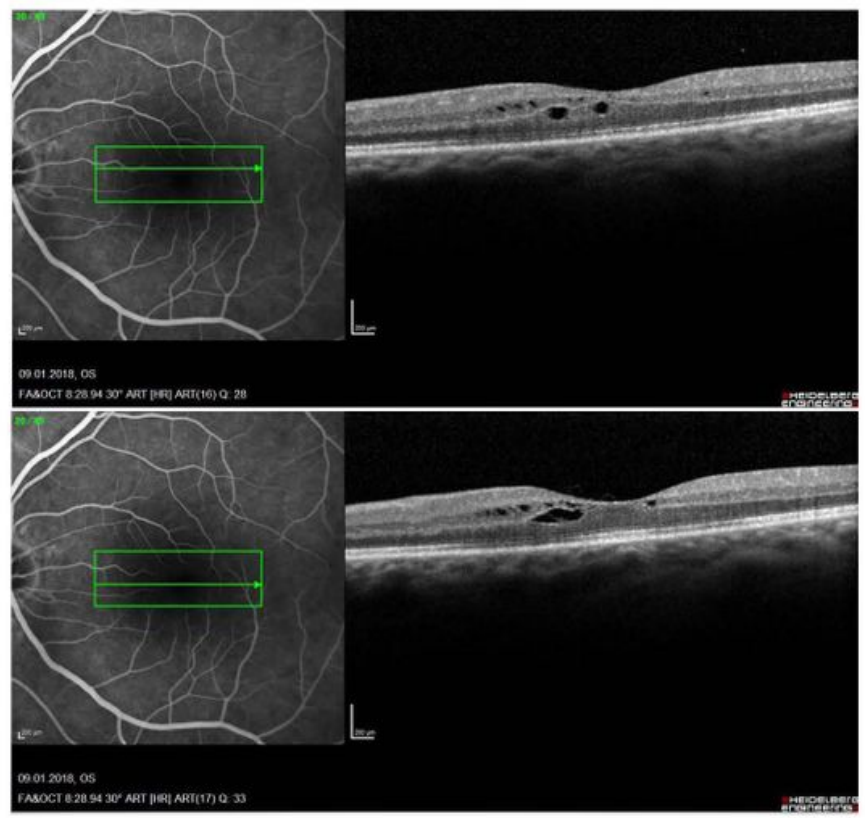

Figure 5 
Figure 5

OCT of the left macula at first presentation
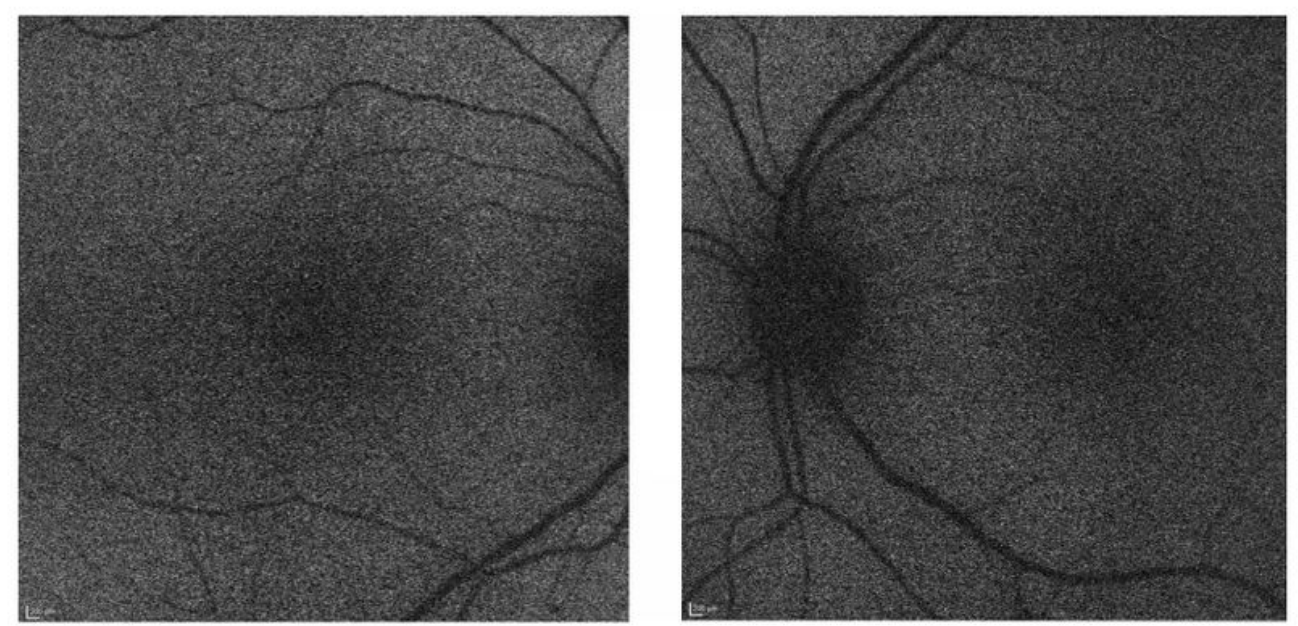

Figure 6

Figure 6

Autofluorescence of the right and left eye at first presentation of the patient 


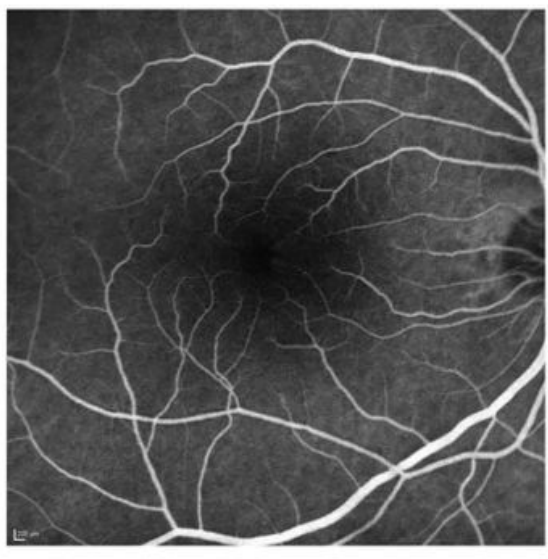

$1 \mathrm{~min} 20 \mathrm{sec}$

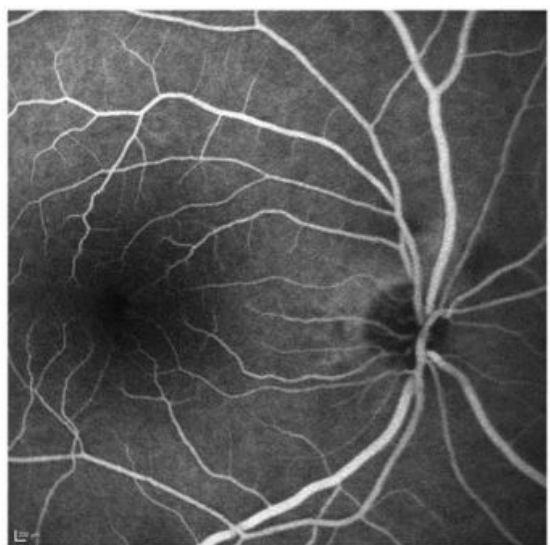

$4 \mathrm{~min} 15 \mathrm{sec}$

Figure 7

\section{Figure 7}

Fluorescence angiography of the right eye at first presentation of the patient

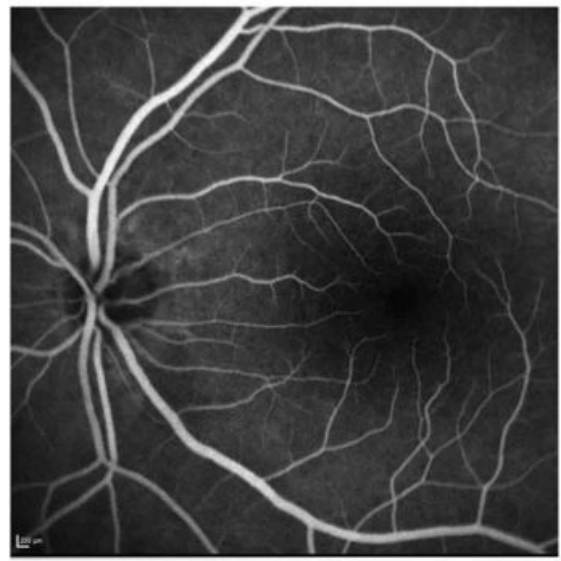

$1 \mathrm{~min} 35 \mathrm{sec}$

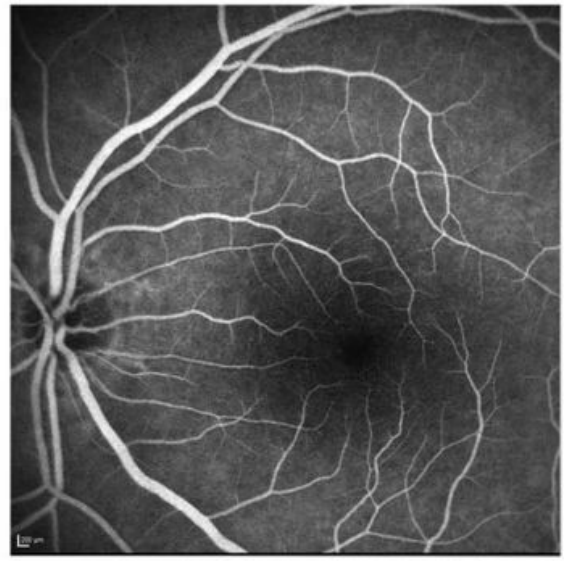

$3 \min 35 \mathrm{sec}$

Figure 8 
Figure 8

Fluorescence angiography of the left eye at first presentation of the patient

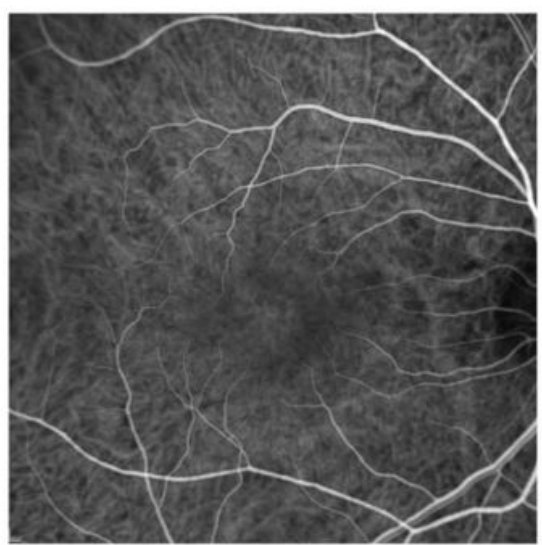

$15 \mathrm{sec}$

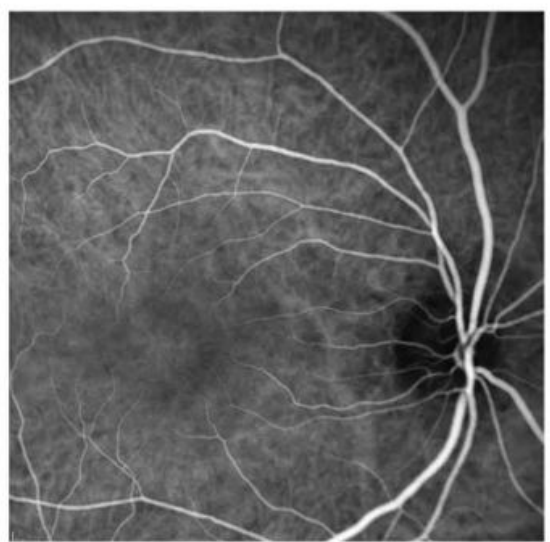

$1 \mathrm{~min} 25 \mathrm{sec}$

Figure 9

Figure 9

ICG of the right eye at first presentation of the patient 


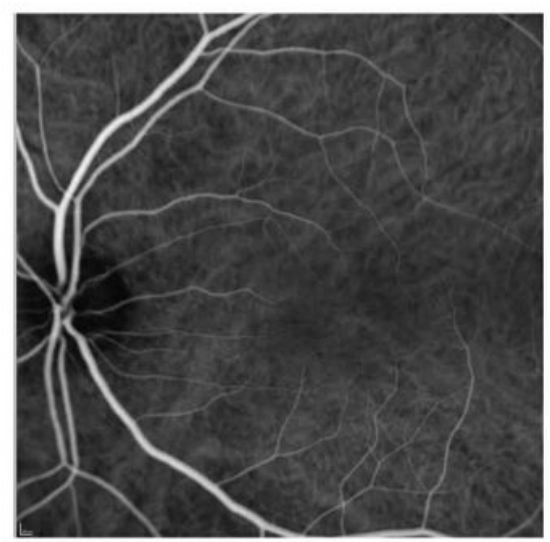

$35 \mathrm{sec}$

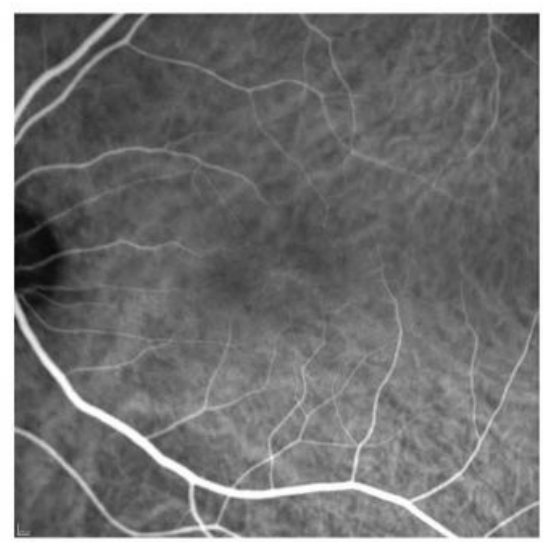

$2 \min 35 \mathrm{sec}$

Figure 10

Figure 10

ICG of the left eye at first presentation of the patient

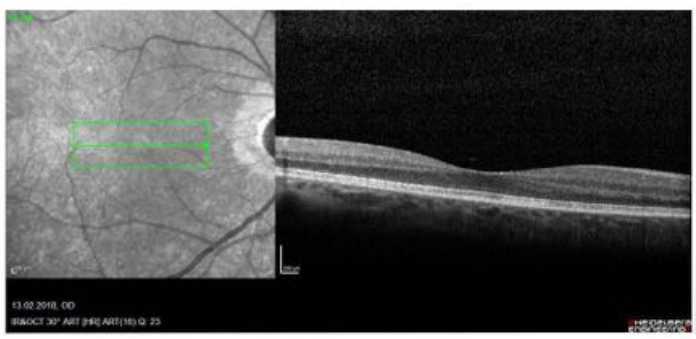

OD

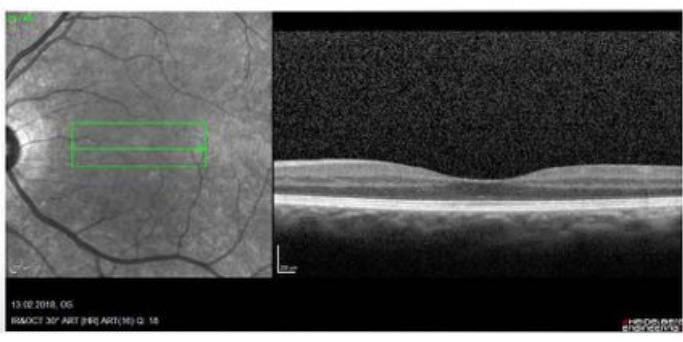

OS

Figure 11 
Figure 11

OCT of the right and left eye- 5 weeks after cessation of Paclitaxel

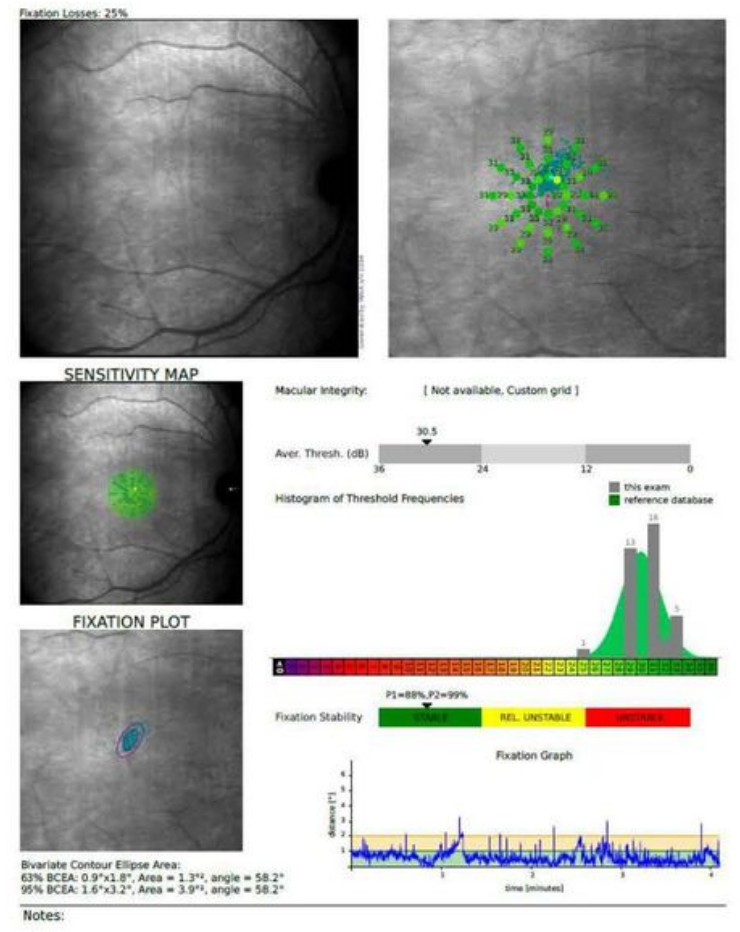

Figure 12

Figure 12

Microperimetry of the right eye; 5 weeks after cessation of Paclitaxel 

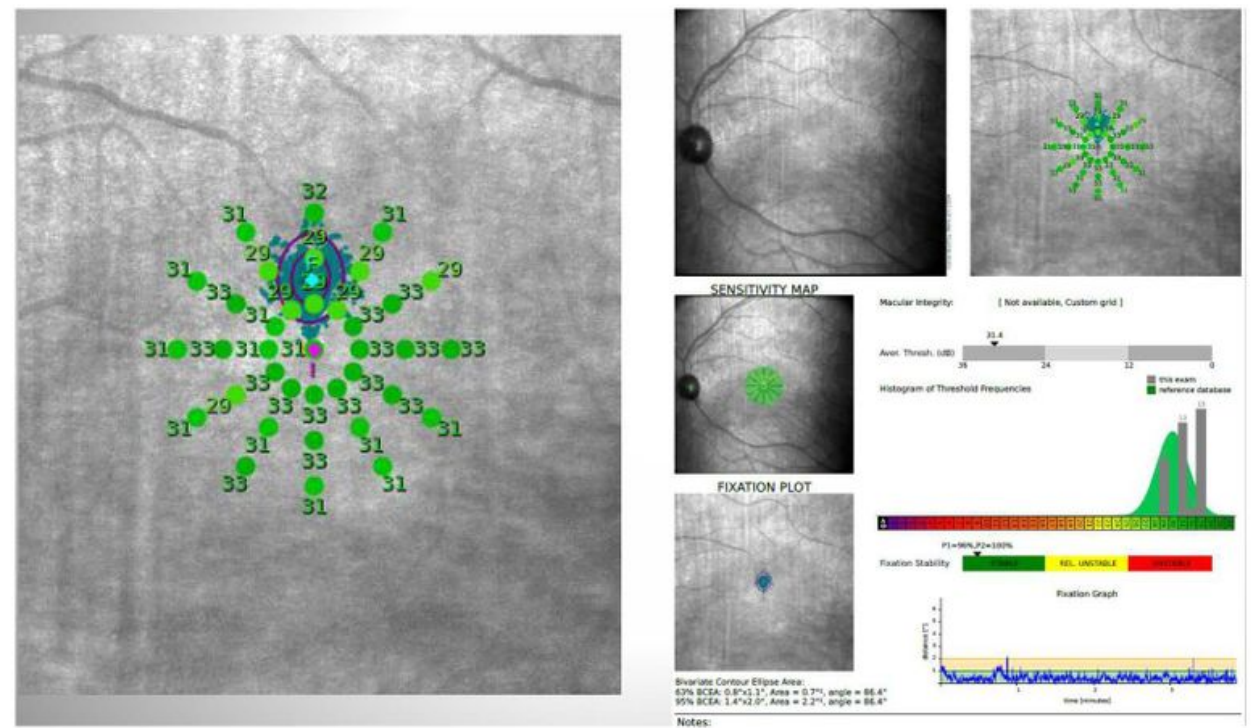

Figure 13

Figure 13

Microperimetry of the left eye; 5 weeks after cessation of Paclitaxel

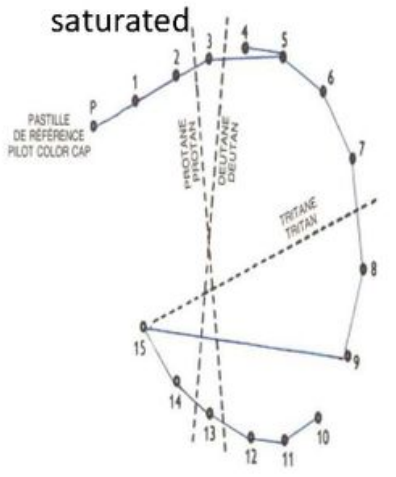

OD
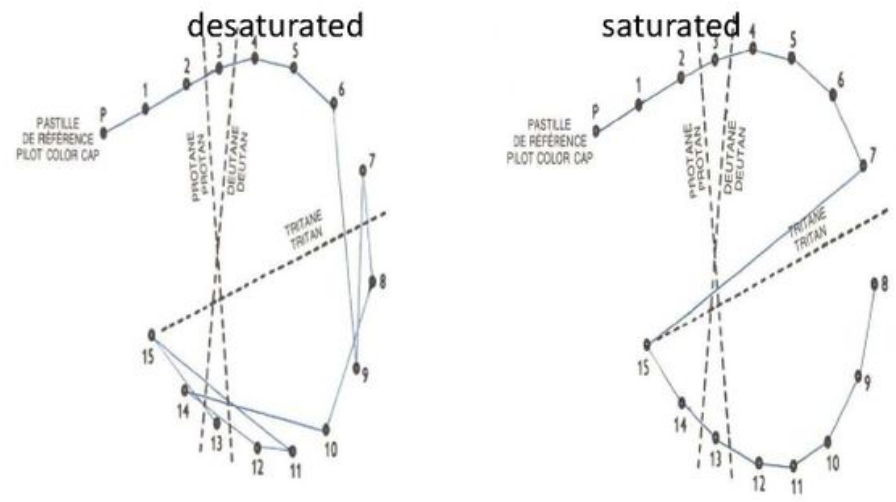

OS

Figure 14 
Figure 14

Color vision of the right and left eye (Panel D15); 5 weeks after cessation of Paclitaxel

\section{Supplementary Files}

This is a list of supplementary files associated with this preprint. Click to download.

- Caredocument.pdf 